\title{
Comparison of single-port laparoscopy and laparotomy in early ovarian cancer surgical staging
}

Kyu Hee Cho, MD ${ }^{1,{ }^{*}}$, Yeon Ju Lee, MD ${ }^{1,{ }^{*}}$, Kyung Jin Eoh, MD, PhD², Yong Jae Lee, MD ${ }^{1}$, Jung-Yun Lee, MD, PhD ${ }^{1}$, Eun Ji Nam, MD, PhD', Sunghoon Kim, MD, PhD ${ }^{1}$, Young Tae Kim, MD, PhD', Sang Wun Kim, MD, PhD ${ }^{1}$

Department of Obstetrics and Gynecology, 'Women's Cancer Center, Yonsei Cancer Center and Institute of Women's Life Medical Science, Severance Hospital, Yonsei University College of Medicine, Seoul, ${ }^{2}$ Yongin Severance Hospital, Yonsei University College of Medicine, Yongin, Korea

\section{Objectives}

The aims of this study were to assess the feasibility of single-port laparoscopic surgical staging (SPLS) in early ovarian cancer and to compare the surgical outcomes of SPLS with those of staging laparotomy.

\section{Methods}

Between January 2014 and December 2018, 40 patients underwent SPLS and 41 patients underwent staging laparotomy at Yonsei Cancer Center. The patients were diagnosed with International Federation of Gynecology and Obstetrics (FIGO) stage I ovarian cancer. Variables such as patient age, body mass index (BMI), tumor size, FIGO stage, and perioperative surgical outcomes and survival outcomes of SPLS and laparotomy were compared.

Results

The total operation time was similar between the 2 groups (SPLS: 201.4 vs. laparotomy: 203.0 minutes, $P=0.806$ ). The median tumor diameters in the SPLS and laparotomy groups were $11.0(2.5-28 \mathrm{~cm})$ and $15.4(6-40 \mathrm{~cm})$, respectively $(P=0.001)$. The SPLS group had lower tumor spillage rate $(5.0 \%$ vs. $19.5 \%, P=0.047)$, less intraoperative blood loss $(102.0$ vs. $371.5 \mathrm{~mL}, P<0.001$ ), less postoperative pain, and shorter postoperative hospital stay ( 5 vs. 9.5 days, $P<0.001$ ). The intraoperative major complication rate was similar between groups $(2.5 \%$ vs. $4.9 \%, P=0.571)$. There was no significant difference in progression-free survival between the 2 groups $(P=0.945)$. There were no deaths in either group.

\section{Conclusion}

SPLS is feasible in early ovarian cancer and has better perioperative surgical outcomes, in some aspects, than staging laparotomy without compromising survival outcomes. SPLS could be performed in patients suspected to have early ovarian cancer.

Keywords: Minimal invasive surgery; Laparoscopic surgery; Laparotomy; Cancer staging; Ovary

\section{Introduction}

Ovarian cancer is the second most common gynecologic malignancy, with the highest mortality rate [1]. Because it is difficult to detect ovarian cancer at an early stage, it is usually not diagnosed until the advanced stage. As with most cancers, ovarian cancer has a high 5 -year relative survival rate $(92.6 \%)$ if detected early [2]. Ovarian cancer is surgically staged, and an optimal staging operation is required to determine the exact stage, treatment plan, and prognosis. The surgical methods for staging ovarian cancer include total hysterectomy, bilateral salpingo-oophorectomy, pelvic and paraaortic lymphadenectomy, omentectomy, peritoneal biopsy,
Received: 2020.07.25. Accepted: 2020.09.18. Published: 2020.10.12. Corresponding author: Sang Wun Kim, MD, PhD

Department of Obstetrics and Gynecology, Women's Cancer Center, Yonsei Cancer Center and Institute of Women's Life Medical Science, Yonsei University College of Medicine, 50-1 Yonsei-ro, Seodaemun-gu, Seoul 03722, Korea

E-mail: san1@yuhs.ac https://orcid.org/0000-0002-8342-8701

${ }^{\star}$ These authors have equally contributed to this paper.

Jung-Yun Lee and Young Tae Kim have been an Editorial Board of Obstetrics \& Gynecology Science; however, they were not involved in the peer reviewer selection, evaluation, or decision process of this article. Otherwise, no other potential conflicts of interest relevant to this article was reported.

Articles published in Obstet Gynecol Sci are open-access, distributed under the terms of the Creative Commons Attribution Non-Commercial License (http://creativecommons. org/licenses/by-nc/3.0/) which permits unrestricted non-commercial use, distribution, and reproduction in any medium, provided the original work is properly cited.

Copyright $\odot 2021$ Korean Society of Obstetrics and Gynecology 


\section{Obstetrics \& Gynecology Science}

Kyu Hee Cho, et al. Single-port laparoscopic staging in ovarian cancer

and peritoneal washing for cytology $[3,4]$.

Recently, many gynecologic surgeries have been performed using a minimally invasive approach compared with the previous invasive approaches, with improved surgical outcomes such as better cosmetic results, less postoperative pain and intraoperative blood loss, and shorter hospital stay. In particular, single-port laparoscopy using a single incision in the umbilicus maximizes the advantages of conventional laparoscopy [5-8].

There have been few studies on single-port laparoscopy for ovarian cancer staging $[9,10]$. Staging laparotomy is still the traditional method, and minimally invasive staging surgery is not widely available owing to limitations in exploring the full extent of the peritoneal surface, port-site metastasis, and a higher incidence of intraoperative tumor rupture $[7,11,12]$. The aims of this study were to introduce and evaluate the safety and feasibility of single-port laparoscopic surgical staging (SPLS), and to compare its perioperative surgical and survival outcomes with those of staging laparotomy in patients with early ovarian cancer.

\section{Materials and methods}

\section{Data collection}

We retrospectively reviewed the medical records of patients who underwent staging surgery for suspected ovarian cancer between January 1, 2014 and December 31, 2018 at Yonsei Cancer Center, Severance Hospital, Yonsei University College of Medicine in Seoul, Korea. During the study period, a total of 1,126 patients were diagnosed with ovarian cancer and underwent surgical staging, of whom 725 patients underwent staging laparotomy and 401 patients underwent staging laparoscopy. In the staging laparoscopy group, 149 patients underwent SPLS. There were 40 patients in the SPLS group and 41 patients in the laparotomy group who were diagnosed with International Federation of Gynecology and Obstetrics (FIGO) stage I ovarian cancer after surgical staging. Patients found to have metastatic cancers or borderline tumors in the final pathology were excluded. Only patients who underwent primary surgical staging at our hospital were included in this study (Fig. 1).

The collected data included patient age, body mass index (BMI), pelvic adhesion, tumor size confirmed with preoperative imaging, tumor histology and grade, preoperative clinical stage, FIGO stage, operation time, estimated blood loss, hemoglobin change, transfusion rate, harvested lymph nodes (LNs), length of hospital stay, intraoperative and postoperative complications, postoperative pain scores (immediately postoperation, postoperative day 1 , and postoperative day 3), postoperative adjuvant chemotherapy, and recurrence rate.

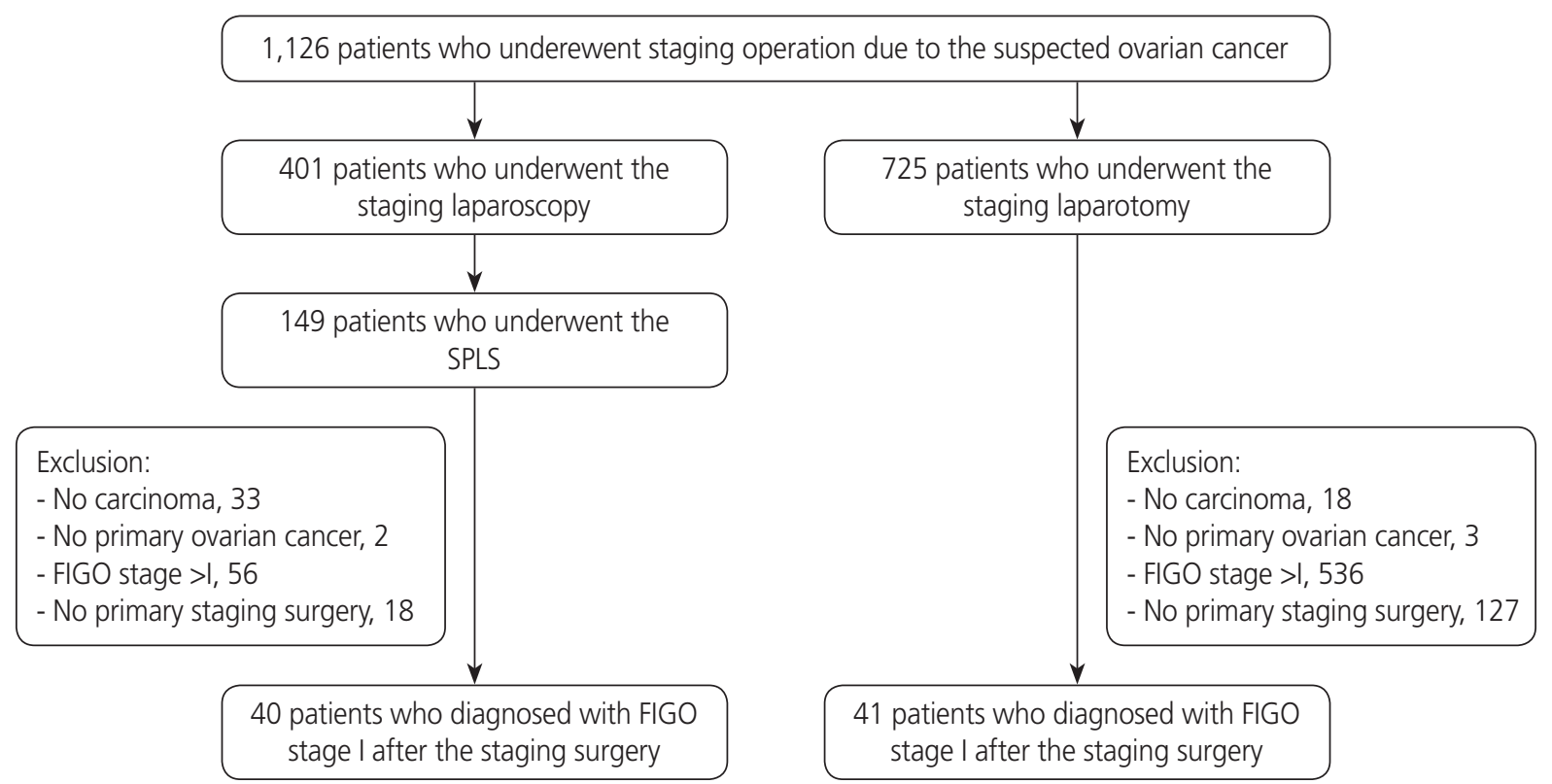

Fig. 1. Flowchart of patient selection. SPLS, single-port laparoscopic surgical staging; FIGO, International Federation of Gynecology and Obstetrics. 


\section{Obstetrics \& Gynecology Science}

Vol. 64, No. 1, 2021

Operative time was defined as the time from skin incision to completion of skin closure. Pain was evaluated using the numeric pain intensity scale (NPIS). Intraoperative complications were defined as adjacent organ or vessel injury, and wound complications were defined as wound discharge, dehiscence, and operative wound herniation. The number of cycles of postoperative adjuvant chemotherapy was compared. Follow-up duration was defined as the number of months from the operation date to the last follow-up date.

\section{Surgical techniques}

\section{1) Single-port laparoscopic surgical staging}

Under general anesthesia, the patient was placed in the lithotomy position and the skin was prepared in the usual manner. A uterine manipulator was used. As in our previous studies, after a $1.2-1.5 \mathrm{~cm}$ vertical intraumbilical skin incision with a $1.5-2.0 \mathrm{~cm}$ rectus fasciotomy was made, an Alexis wound retractor (Applied Medical, Rancho Santa Margarita, CA, USA) was inserted through the umbilical incision and a surgical glove was combined with the Alexis wound retractor for a single-port entry system (Fig. 2A). Subsequently, the abdominal cavity was filled with $\mathrm{CO}_{2}$ gas and the patient was placed in the Trendelenburg position $[13,14]$.

After the pelvic and abdominal cavities were thoroughly explored, peritoneal washing cytology samples were obtained first. Thereafter, each procedure (e.g., hysterectomy, salpingo-oophorectomy, lymphadenectomy, omentectomy, peritonectomy, and appendectomy) was performed using bipolar or monopolar electrocautery and LigaSure (Covidien Valleylab, Boulder, CO, USA) or the Thunderbeat system (Olympus Medical Systems Corp., Tokyo, Japan) [4].

To avoid spilling into the intraperitoneal cavity, ovarian tumors were removed using a laparoscopic tissue retrieval bag (LapBag; Sejong Medical Co., Ltd., Seoul, Korea) (Fig. 2B and $C$ ). In the case of large tumors (longest diameter $\geq 15 \mathrm{~cm}$ ),

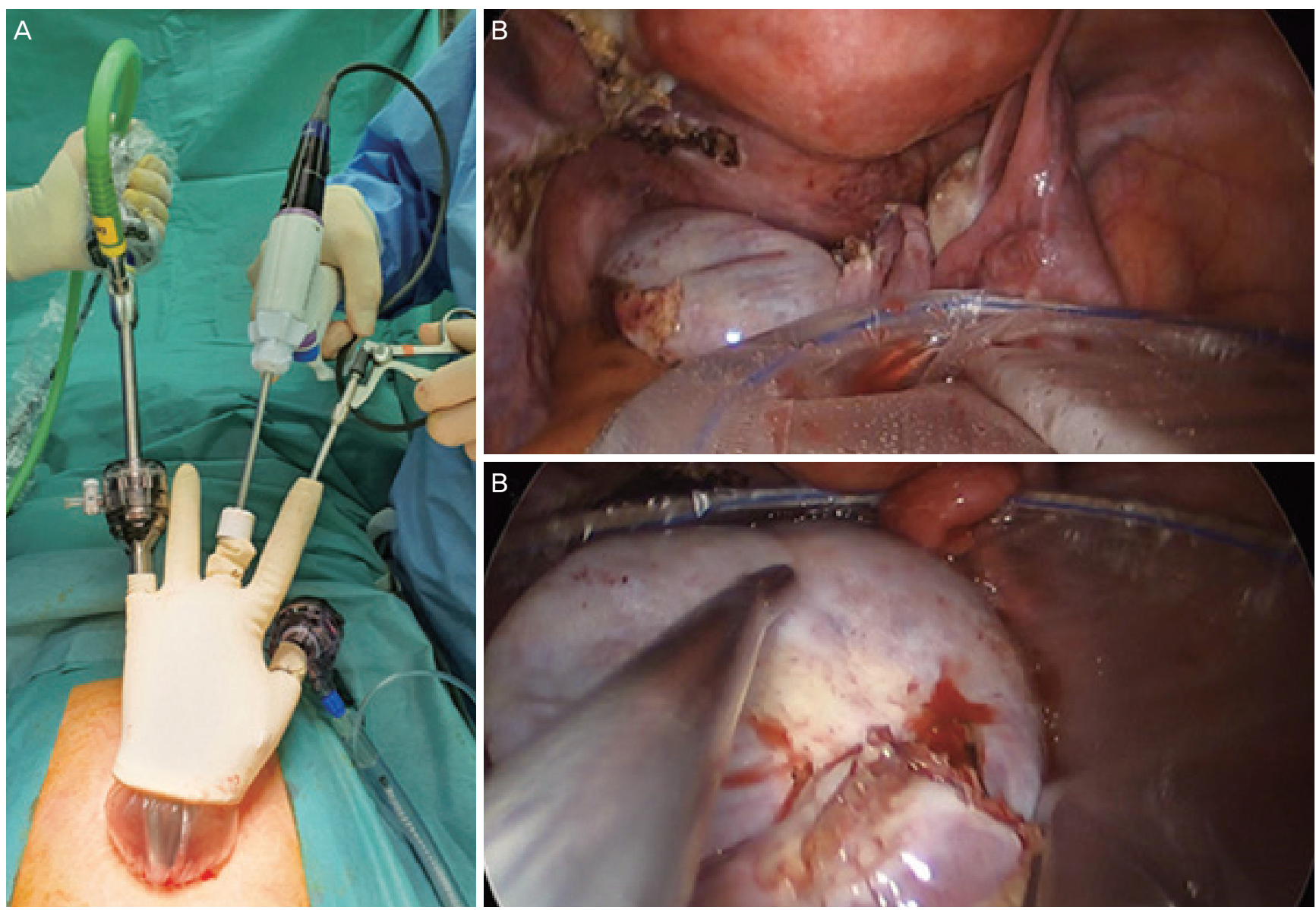

Fig. 2. Single-port laparoscopic surgical staging outside view $(A)$ and safe tumor removal using a laparoscopic tissue retrieval bag (B, $C)$. 


\section{Obstetrics \& Gynecology Science}

Kyu Hee Cho, et al. Single-port laparoscopic staging in ovarian cancer

SW Kim's technique was used to insert the tumors in a retrieval bag [15], the bag was retracted through the umbilicus, and the tumor was removed by aspirating and cutting it inside the bag. After hemostasis and irrigation, the Alexis wound retractor was removed and the umbilical fascia and subcutaneous layer were approximated with 1-0 and 2-0 Vicryl sutures (Ethicon, Piscataway, NJ, USA) $[13,14]$.

\section{2) Staging laparotomy}

The preoperative preparation, surgical procedures, and postoperative management were essentially the same as for SPLS, except for a low midline or extended midline incision and nonuse of $\mathrm{CO}_{2}$ gas.

\section{Statistical methods}

Statistical analysis was performed using SPSS version 25 (IBM, Armonk, NY, USA). A P-value of $<0.05$ was considered statistically significant. Categorical variables are presented as frequencies and percentages, and the Pearson $\chi^{2}$ test was used to evaluate differences between proportions. For continuous variables, medians and ranges of variables are presented, and the Mann-Whitney $U$ test was performed. Kaplan-Meier estimates were used to evaluate differences in time to recurrence (Fig. $3 \mathrm{~A}$ and $\mathrm{B}$ ), and propensity score matching was used to adjust for selection bias (Supplementary Table 1) [16-18].

\section{Results}

In total, 81 patients who underwent surgical staging for early ovarian cancer were selected (40 SPLS and 41 laparotomy). In the SPLS group, 1 patient (2.5\%) was converted to staging laparotomy because of a large tumor and 3 patients (7.5\%) required an additional port.

The patient characteristics are shown in Table 1. The median age of patients in the SPLS group was younger than that of patients in the laparotomy group (46.4 [15-86] vs. 53.8 [19-61] years, $P=0.005$ ). There was no significant difference in median BMI (24.0 [15.0-36.8] vs. 23.2 [16.7-32.9] $\left.\mathrm{kg} / \mathrm{m}^{2}, P=0.461\right)$ or pelvic adhesion rate $(50.0 \%$ vs. $39.0 \%$, $P=0.320)$. The median tumor size was $11 \mathrm{~cm}$ in the $S P L S$ group and $15.4 \mathrm{~cm}$ in the laparotomy group ( $P=0.001)$. The most common tumor histology type in the SPLS group was mucinous adenocarcinoma (30.0\%), followed by clear cell carcinoma $(25.0 \%)$, sex cord-stromal tumor $(12.5 \%)$, and endometrioid adenocarcinoma (10.0\%). In the laparotomy group, mucinous $(22.0 \%)$ and endometrioid $(22.0 \%)$ adenocarcinomas were the most common histologic types, followed by serous adenocarcinoma (19.5\%) and clear cell carcinoma (19.5\%). The tumor grade was not significantly different between the 2 groups (SPLS group vs. laparotomy group, grade $1: 27.5 \%$ vs. $17.1 \%$, grade $2: 20.0 \%$ vs. $34.1 \%$, grade 3 : $25.0 \%$ vs. $24.4 \%$; $P=0.464)$. With respect to the FIGO stage, stage IA was the most common stage in both groups (70.0\% and $39.0 \%$ in the SPLS and laparotomy groups, respectively), and the SPLS group had more stage IA cases ( $P=0.010)$. FIGO stage IC1 constituted $5.0 \%$ and $19.5 \%$, IC2 $20.0 \%$ and $22.0 \%$, and IC $2.5 \%$ and $19.5 \%$ in the SPLS and laparotomy groups, respectively.

Of 149 patients who underwent SPLS for suspected ovar-
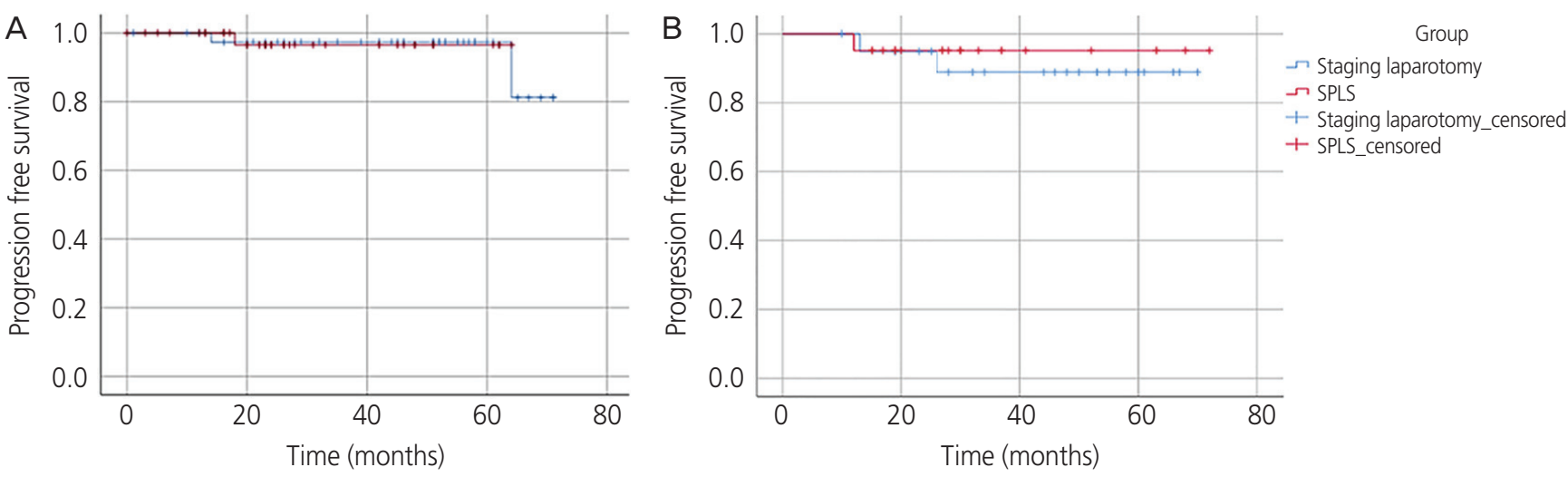

Fig. 3. Comparison of survival curves between single-port laparoscopic surgical staging (SPLS) and staging laparotomy. (A) Before propensity score matching (SPLS, $n=40$ and staging laparotomy, $n=41)$. (B) After propensity score matching (SPLS, $n=21$ and staging laparotomy, $\mathrm{n}=21$ ). 


\title{
Obstetrics \& Gynecology Science
}

\author{
Vol. 64, No. 1, 2021
}

ian cancer, 96 patients were finally diagnosed with ovarian cancer after the surgery. Table 2 shows the preoperative clinical stage and postoperative FIGO stage of patients who were finally diagnosed with ovarian cancer. Fourteen patients (14.6\%) were upstaged from preoperative clinical stage I to postoperative FIGO stage II to IV (FIGO stage II: 10 patients, stage III: 3 patients, and stage IV: 1 patient).

Furthermore, we performed propensity score matching to minimize the difference in clinical characteristics between the

Table 1. Patient characteristics in the single-port laparoscopic surgical staging (SPLS) and staging laparotomy groups $(n=81)$

\begin{tabular}{|c|c|c|c|}
\hline Characteristics & SPLS $(n=40)$ & $\begin{array}{l}\text { Staging lapa- } \\
\text { rotomy }(n=41)\end{array}$ & $P$-value \\
\hline Age (yr) & $46.4(15-86)$ & $53.8(19-61)$ & $0.005^{a)}$ \\
\hline $\mathrm{BMI}\left(\mathrm{kg} / \mathrm{m}^{2}\right)$ & $24(15.0-36.8)$ & $23.2(16.7-32.9)$ & $0.461^{\mathrm{a})}$ \\
\hline Pelvic adhesion & $20(50)$ & $16(39.0)$ & $0.320^{b)}$ \\
\hline Tumor size (cm) & $11(2.5-28)$ & $15.4(6-40)$ & $0.001^{\mathrm{a})}$ \\
\hline FIGO stage & & & $0.010^{b)}$ \\
\hline IA & $28(70.0)$ & $16(39.0)$ & \\
\hline $\mathrm{IB}$ & $0(0.0)$ & $0(0.0)$ & \\
\hline IC1 & $2(5.0)$ & $8(19.5)$ & \\
\hline IC2 & $8(20.0)$ & $9(22.0)$ & \\
\hline IC3 & $1(2.5)$ & $8(19.5)$ & \\
\hline Unknown & $1(2.5)$ & $0(0.0)$ & \\
\hline Histology & & & $0.111^{b)}$ \\
\hline Serous & $3(7.5)$ & $8(19.5)$ & \\
\hline Mucinous & $12(30.0)$ & $9(22.0)$ & \\
\hline Seromucinous & $2(5.0)$ & $3(7.3)$ & \\
\hline Endometrioid & $4(10.0)$ & $9(22.0)$ & \\
\hline Clear cell & $10(25.0)$ & $8(19.5)$ & \\
\hline $\begin{array}{l}\text { Malignant germ } \\
\text { cell }\end{array}$ & $1(2.5)$ & $3(7.3)$ & \\
\hline Sex cord-stromal & $5(12.5)$ & $1(2.4)$ & \\
\hline Others & $3(7.5)$ & $0(0.0)$ & \\
\hline Tumor grade & & & $0.464^{b)}$ \\
\hline Grade 1 & $11(27.5)$ & $7(17.1)$ & \\
\hline Grade 2 & $8(20.0)$ & $14(34.1)$ & \\
\hline Grade 3 & $10(25.0)$ & $10(24.4)$ & \\
\hline N/A & $11(27.5)$ & $10(24.4)$ & \\
\hline
\end{tabular}

Data are presented as median (range) or number (\%).

BMI, body mass index; N/A, not applicable; FIGO, 2014 International Federation of Gynecology and Obstetrics.

${ }^{\text {a) }}$ Calculated using the Mann-Whitney nonparametric test; ${ }^{\text {b) }} \mathrm{Calcu}-$ lated using the $\chi^{2}$ parametric test. two groups. The number of patients after propensity score matching decreased to 21 in each group, and the patient characteristics are summarized in Supplementary Table 1.

There was no significant difference between the 2 groups in terms of surgical procedures (Table 3 ). The number of harvested LNs (14.3 vs. 21.0, $P=0.145)$, total operation time (201.4 vs. 203.0 minutes, $P=0.806$ ), and postoperative hemoglobin change ( 2.1 vs. $2.2 \mathrm{~g} / \mathrm{dL}, P=0.981$ ) did not differ between the SPLS and laparotomy groups. The estimated blood loss was smaller in the SPLS group (median: $102 \mathrm{~mL}$, range: $10-1,100 \mathrm{~mL}$ ) than in the laparotomy group (median: $371.5 \mathrm{~mL}$, range: $10-1,870 \mathrm{~mL})(P<0.001)$. Moreover, the intraoperative transfusion rate was lower in the SPLS group (1/40 [2.5\%] vs. $8 / 41$ [19.5\%], $P=0.015)$. The SPLS group showed lower postoperative pain score (immediately postoperation: $5.2[2-7]$ vs. 6.0 [2-9], $P=0.003$; postoperative day 1: $3.7[2-8]$ vs. $4.9[2-10], P=0.004$; postoperative day 3 : 2.9 [1-7] vs. $3.5[2-7], P=0.017)$ and shorter postoperative hospital stay ( 5 vs. 9.5 days, $P<0.001$ ). The intraoperative major complication rate was similar between groups $(2.5 \%$ vs. $4.9 \%, P=0.571)$. The SPLS group had 1 case of vascular injury, and the laparotomy group had 2 cases of bowel injury. There were no wound complications such as wound dehiscence or umbilical hernia in the SPLS group, whereas wound discharge was observed in 2 patients in the laparotomy group.

The adjuvant chemotherapy rate was lower in the SPLS group than in the laparotomy group $(40.0 \%$ vs. $75.6 \%$, $P=0.001$ ) (Table 4). The median number of chemotherapy cycles was similar in the two groups (5.1 vs. 5.3 cycles, $P=0.426)$. The SPLS group showed a longer time to chemotherapy after the surgery ( 17.3 vs. 15.3 days, $P=0.031$ ).

Table 2. Comparison of preoperative clinical stage and postoperative surgical stage in patients who were diagnosed with ovarian cancer after single-port laparoscopic surgical staging $(n=96)$

\begin{tabular}{ccccccc}
\hline & \multicolumn{7}{c}{ Postoperative FIGO stage } \\
\cline { 2 - 7 } & & I & II & III & IV & Total \\
\hline & I & 40 & 10 & 3 & 0 & 53 \\
Preoperative & II & 0 & 4 & 0 & 0 & 4 \\
clinical stage & III & 0 & 0 & 24 & 1 & 25 \\
& IV & 0 & 0 & 0 & 14 & 14 \\
& Total & 40 & 14 & 27 & 15 & \\
\hline
\end{tabular}

FIGO, 2014 International Federation of Gynecology and Obstetrics. 


\section{Obstetrics \& Gynecology Science}

Kyu Hee Cho, et al. Single-port laparoscopic staging in ovarian cancer

Table 3. Surgical outcomes of single-port laparoscopic surgical staging (SPLS, $n=40)$ and staging laparotomy $(n=41)$

\begin{tabular}{|c|c|c|c|}
\hline Surgical outcomes & SPLS $(n=40)$ & $\begin{array}{l}\text { Staging laparotomy } \\
(n=41)\end{array}$ & $P$-value \\
\hline \multicolumn{4}{|l|}{ Procedures } \\
\hline Hysterectomy & $30(75.0)$ & $33(80.5)$ & \\
\hline Unilateral salpingo-oophorectomy & $15(37.5)$ & $3(7.3)$ & \\
\hline Bilateral salpingo-oophorectomy & $24(60.0)$ & $38(92.7)$ & \\
\hline Lymphadenectomy & $34(85.0)$ & $39(95.1)$ & \\
\hline Omentectomy & $32(80.0)$ & $37(90.2)$ & \\
\hline Appendectomy & $6(15.0)$ & $27(65.9)$ & \\
\hline Peritonectomy & $14(35.0)$ & $11(26.8)$ & \\
\hline Others & $7(17.5)$ & $7(17.1)$ & \\
\hline Harvested LNs & $14.3(0-46)$ & $21.1(0-72)$ & $0.145^{\text {a) }}$ \\
\hline Operation time (min) & $201.4(92-412)$ & $203.0(92-521)$ & $0.806^{\mathrm{a})}$ \\
\hline $\mathrm{EBL}(\mathrm{mL})$ & $102(10-1,100)$ & $371.5(10-1,870)$ & $<0.001^{\text {a) }}$ \\
\hline $\mathrm{Hb}$ changes (g/dL) & $2.1(0.3-4.2)$ & $2.2(0.7-4.1)$ & $0.981^{\text {a) }}$ \\
\hline Intraoperative transfusion & $1(2.5)$ & $8(19.5)$ & $0.015^{b)}$ \\
\hline \multicolumn{4}{|l|}{ Pain score (NPIS) } \\
\hline Immediately post-operation & $5.2(2-7)$ & $6.0(2-9)$ & $0.003^{\mathrm{a})}$ \\
\hline POD\#1 & $3.7(2-8)$ & $4.9(2-10)$ & $0.004^{a)}$ \\
\hline POD\#3 & $2.9(1-7)$ & $3.5(2-7)$ & $0.017^{\text {a) }}$ \\
\hline Postoperative hospital stay (day) & $5(2-9)$ & $9.5(5-20)$ & $<0.001^{\text {a) }}$ \\
\hline Intraoperative complications & $1(2.5)$ & $2(4.9)$ & $0.571^{b)}$ \\
\hline Bowel injury & $0(0.0)$ & $2(4.9)$ & \\
\hline Vessel injury & $1(2.5)$ & $0(0.0)$ & \\
\hline Wound complications & $0(0.0)$ & $2(4.9)$ & $0.157^{b)}$ \\
\hline Wound discharge & $0(0.0)$ & $2(4.9)$ & \\
\hline Hernia & $0(0.0)$ & $0(0.0)$ & \\
\hline
\end{tabular}

Data are presented as median (range) or number (\%).

LN, lymph node; EBL, estimated blood loss; Hb, hemoglobin; NPIS, numeric pain intensity scale; POD, postoperative day.

${ }^{a)}$ Calculated using the Mann-Whitney nonparametric test; ${ }^{\text {b) }}$ Calculated using the $\chi^{2}$ parametric test.

Table 4. Postoperative adjuvant chemotherapy rate in the 2 groups

\begin{tabular}{lccc}
\hline Variables & SPLS (n=40) & $\begin{array}{c}\text { Staging laparotomy } \\
(\mathbf{n}=\mathbf{4 1})\end{array}$ & $\boldsymbol{P}$-value \\
\hline Adjuvant chemotherapy & $16(40.0)$ & $31(75.6)$ & $0.001^{\mathrm{b})}$ \\
Cycles of chemotherapy & $5.1(3-6)$ & $5.3(1-8)$ & $0.426^{\mathrm{a})}$ \\
Time to chemotherapy (day) & $17.3(7-31)$ & $15.3(6-25)$ & $0.031^{\mathrm{a})}$ \\
\hline
\end{tabular}

Data are presented as median (range) or number (\%).

SPLS, single-port laparoscopic surgical staging.

${ }^{\text {a) }}$ Calculated using the Mann-Whitney nonparametric test; ${ }^{\text {b) }}$ Calculated using the $\chi^{2}$ parametric test. 


\title{
Obstetrics \& Gynecology Science
}

\author{
Vol. 64, No. 1, 2021
}

The median follow-up time was 35.8 months (range, 15-72 months) in the SPLS group and 48.2 months (range, 10-74 months) in the laparotomy group. There was no significant difference in recurrence rate $(1 / 40[2.5 \%]$ vs. $2 / 41$ $[4.9 \%], P=0.571)$. The values for progression-free survival were compared using Kaplan-Meier survival curves, and no significant difference was found between the two groups in all patients $(P=0.945)$ (Fig. $3 A)$ and after propensity score matching ( $P=0.594)$ (Fig. 3B). There were no deaths in either group during the study period.

\section{Discussion}

Many studies have compared open surgery and laparoscopic surgery in gynecology. Furthermore, several studies have compared conventional laparoscopy using multiple ports and laparotomy in ovarian cancer $[9,18,19-21]$. However, no previous study has compared single-port laparoscopic surgery and laparotomy in ovarian cancer, although several studies have compared single-port and multiport laparoscopic surgery for benign gynecologic diseases $[13,22]$. Therefore, this study is the first to investigate the feasibility of single-port laparoscopic surgery by comparing SPLS and staging laparotomy in early ovarian cancer.

According to our results, SPLS has several advantages in terms of surgical outcomes, such as lower estimated blood loss, lower transfusion rate, less postoperative pain, and shorter postoperative hospital stay, while showing no significant differences in survival outcomes. Less blood loss is well known as one of the main advantages of minimally invasive surgery. In this study, there was less blood loss in the SPLS group than in the laparotomy group; however, the change in hemoglobin after surgery did not differ between the 2 groups. This may be attributed to the increased transfusion rate during surgery in the staging laparotomy group. There were no significant differences in perioperative complications and postoperative wound complications.

The patients' BMI and pelvic adhesion did not significantly affect the surgical methods used in this study. However, tumor size is usually a major concern in selecting laparoscopic surgery, especially in patients with possible malignant ovarian tumors. If the ovarian tumor is too large, it is usually difficult to remove safely, which is a limitation to performing laparoscopic surgery. Thus, most surgeons usually prefer laparoto- my for large ovarian tumors. Nevertheless, there have been several attempts to perform minimally invasive surgeries even with large ovarian tumors, and we previously reported a technique for removing large ovarian tumors without aspiration or rupture in single-port laparoscopic surgery [15]. By using a large endoscopic bag, such as a $30 \times 30 \mathrm{~cm}$ or $50 \times 50$ $\mathrm{cm}$ endoscopic tissue retrieval bag, huge ovarian tumors could be removed without any tumor spillage or cystic fluid aspiration. In this study, SPLS was successfully performed in most patients and showed a relatively lower tumor rupture rate than laparotomy (5\% vs. $19.5 \%$ ). However, in some patients, SPLS may require an additional port or conversion to laparotomy, especially when the tumor has severe adhesions.

The number of patients diagnosed with FIGO stage IA ovarian cancer was higher in the SPLS group. Accordingly, the postoperative adjuvant chemotherapy rate was lower in the SPLS group than in the laparotomy group. This may be associated with the relatively larger tumor size and higher tumor spillage rate in the laparotomy group. Although the laparotomy group had more patients with higher-stage disease in this study, there was no statistically significant difference in progression-free or overall survival rates between the 2 groups.

Our study was a retrospective study, and there may be some bias in the study design (i.e., review of electronic medical records). The sample size was too small to represent the entire population. A single surgeon performed all operations in the SPLS group, whereas multiple surgeons performed the operations in the staging laparotomy group. Each patient had a different duration of follow-up, and the follow-up period was $<1$ year in some patients; thus, there were insufficient data on cancer relapse or death. Further prospective randomized comparison studies are needed to confirm the safety of SPLS in terms of survival outcomes.

In conclusion, SPLS has several advantages in terms of blood loss, postoperative pain, and hospital stay, without compromising survival outcomes. SPLS, when performed by experienced gynecologic oncology surgeons, may be feasible and safe in the surgical staging of early ovarian cancer.

\section{Conflict of interest}

No potential conflict of interest relevant to this article was reported. 


\section{Obstetrics \& Gynecology Science}

Kyu Hee Cho, et al. Single-port laparoscopic staging in ovarian cancer

\section{Ethical approval}

This study was approved by the Institutional Review Board of Severance Hospital (4-2020-0366).

\section{Patient consent}

The Institutional Review Board approved the exemption of patients' consent under the restriction that no identifiable personal information is revealed in the process.

\section{Funding information}

None.

\section{Supplementary material}

Supplementary Table 1 associated with this article can be found online at https://doi.org/10.5468/ogs.20216.

\section{References}

1. Siegel RL, Miller KD, Jemal A. Cancer statistics, 2019. CA Cancer J Clin 2019;69:7-34.

2. Howlader N, Noone A, Krapcho M, Miller D, Brest A, Yu M. SEER Cancer Statistics Review, 1975-2017. Bethesda (MD): National Cancer Institute. 2020.

3. Trimbos JB. Surgical treatment of early-stage ovarian cancer. Best Pract Res Clin Obstet Gynaecol 2017;41:6070.

4. Sonoda Y, Barakat RR. Laparoscopic staging procedures. In: Levine DA, Barakat RR, Hoskins WJ, editors. Atlas of Procedures in Gynecologic Oncology. Boca Raton (FL): Taylor \& Francis; 2003. p.103-30.

5. Fagotti A, Bottoni C, Vizzielli G, Gueli Alletti S, Scambia $G$, Marana $E$, et al. Postoperative pain after conventional laparoscopy and laparoendoscopic single site surgery (LESS) for benign adnexal disease: a randomized trial. Fertil Steril 2011;96:255-259.e2.

6. Chong GO, Hong DG, Lee YS. Single-port (OctoPort) assisted extracorporeal ovarian cystectomy for the treat- ment of large ovarian cysts: compare to conventional laparoscopy and laparotomy. J Minim Invasive Gynecol 2015;22:45-9.

7. Schmitt $A$, Crochet $P$, Knight $S$, Tourette $C$, Loundou A, Agostini A. Single-port laparoscopy vs conventional laparoscopy in benign adnexal diseases: a systematic review and meta-analysis. J Minim Invasive Gynecol 2017;24:1083-95.

8. Lee IO, Yoon JW, Chung D, Yim GW, Nam EJ, Kim S, et al. A comparison of clinical and surgical outcomes between laparo-endoscopic single-site surgery and traditional multiport laparoscopic surgery for adnexal tumors. Obstet Gynecol Sci 2014;57:386-92.

9. Moulton L, Jernigan AM, Carr C, Freeman L, Escobar PF, Michener CM. Single-port laparoscopy in gynecologic oncology: seven years of experience at a single institution. Am J Obstet Gynecol 2017;217:610.e1-8.

10. Carbajal-Mamani SL, Schweer D, Markham MJ, Esnakula AK, Grajo JR, Castagno JC, et al. Robotic-assisted interval cytoreductive surgery in ovarian cancer: a feasibility study. Obstet Gynecol Sci 2020;63:150-7.

11. Weber S, McCann CK, Boruta DM, Schorge JO, Growdon WB. Laparoscopic surgical staging of early ovarian cancer. Rev Obstet Gynecol 2011;4:117-22.

12. Lu Q, Qu H, Liu C, Wang S, Zhang Z, Zhang Z. Comparison of laparoscopy and laparotomy in surgical staging of apparent early ovarian cancer: 13-year experience. Medicine (Baltimore) 2016;95:e3655.

13. Yim GW, Jung YW, Paek J, Lee SH, Kwon HY, Nam EJ, et al. Transumbilical single-port access versus conventional total laparoscopic hysterectomy: surgical outcomes. Am J Obstet Gynecol 2010;203:26.e1-6.

14. Yim GW, Lee M, Nam EJ, Kim S, Kim YT, Kim SW. Is single-port access laparoscopy less painful than conventional laparoscopy for adnexal surgery? A comparison of postoperative pain and surgical outcomes. Surg Innov 2013;20:46-54.

15. Kim JS, Lee IO, Eoh KJ, Chung YS, Lee I, Lee JY, et al. Surgical technique for single-port laparoscopy in huge ovarian tumors: SW Kim's technique and comparison to laparotomy. Obstet Gynecol Sci 2017;60:178-86.

16. Rosenbaum PR, Rubin DB. Reducing bias in observational studies using subclassification on the propensity score. J Am Stat Assoc 1984;79:516-24.

17. Deeks JJ, Dinnes J, D’Amico R, Sowden AJ, Sakarovitch 


\section{Obstetrics \& Gynecology Science}

Vol. 64, No. 1, 2021

$C$, Song $F$, et al. Evaluating non-randomised intervention studies. Health Technol Assess 2003;7:iii-x.

18. Thoemmes F. Propensity score matching in SPSS. arXiv 2012:1201.6385.

19. Park JY, Bae J, Lim MC, Lim SY, Seo SS, Kang S, et al. Laparoscopic and laparotomic staging in stage I epithelial ovarian cancer: a comparison of feasibility and safety. Int J Gynecol Cancer 2008;18:1202-9.

20. Figurelli J, Bresson L, Narducci F, Katdare N, Coulon P, Fournier $C$, et al. Single-port access laparoscopic surgery in gynecologic oncology: outcomes and feasibility. Int J
Gynecol Cancer 2014;24:1126-32.

21. Gallotta V, Petrillo M, Conte C, Vizzielli G, Fagotti A, Ferrandina $G$, et al. Laparoscopic versus laparotomic surgical staging for early-stage ovarian cancer: a case-control study. J Minim Invasive Gynecol 2016;23:769-74.

22. Kim MS, Choi CH, Lee JW, Kim BG, Bae DS, Kim TJ. Comparison between laparoendoscopic single-site and conventional laparoscopic surgery in mature cystic teratoma of the ovary. Gynecol Minim Invasive Ther 2019;8:155-9. 